\title{
Atomic bomb testing and its effects on global male to female ratios at birth
}

\author{
Victor Grech* \\ Department of Paediatrics, Mater Dei Hospital, Malta
}

Received 15 September 2014

Accepted 24 January 2015

\begin{abstract}
.
AIMS: Fallout from atomic bomb testing may travel great distances before precipitating. Males are born in excess of females in a ratio that approximates 0.515 (M/T: male live births divided by total live births. Radiation increases M/T by causing lethal malformations that affect female more than male foetuses, decreasing total births. This study was carried out in order to ascertain whether the effects of increased background radiation levels from atomic weapon testing had any widespread effects on M/T and births in the Americas, Europe, Asia and Australasia in relation to the Partial Test Ban Treaty of 1963.

METHODS: Annual live births by gender were obtained from a World Health Organization dataset and annual number of atomic bomb tests were also obtained (historical data).

RESULTS: Overall, 94.5\% of births studied showed a uniform reduction in M/T between the early 1950s to the late 1960s, followed by an increase to the mid-1970s, with a subsequent decline. A negative correlation of M/T with total births was found in $66 \%$ of births studied, and these were the regions which exhibited the rising M/T pattern in the 1970s. The birth deficit for countries with significant correlations of total births with M/T (North America, Europe and Asia) was estimated at 10090701. CONCLUSIONS: A rising M/T was found in most regions in temporal association with atomic weapon testing. Most of these regions also had an associated decline in total births. Elevated levels of man-made ambient radiation may have reduced total births, affecting pregnancies carrying female pregnancies more than those carrying male pregnancies, thereby skewing $\mathrm{M} / \mathrm{T}$ toward a higher male proportion.
\end{abstract}

Keywords: Birth Rate/*trends, radiation, ionizing, sex ratio, infant, newborn

\section{Introduction}

The atomic era was ushered in by the Trinity test explosion at Alamogordo in New Mexico in July 1945 [1]. The above-ground detonation of nuclear devices deposits substantial quantities of radioactive particles into the atmosphere to very high elevations. While larger and heavier particles tend to drop out close to the site of the explosion, smaller and lighter particles may remain aloft for decades and travel great distances before depositing out of the atmosphere spontaneously or via rainfall, as fallout, widely distributing radiation and increasing background radiation counts [2]. Fallout consists of hundreds of different radionuclides with variable half-lives ranging from minutes to many years. Exposure to fallout

\footnotetext{
*Address for correspondence: Victor Grech, Department of Paediatrics, Mater Dei Hospital, Malta. Tel.: +356 2340 2340; Fax: +356 2340 2342; E-mail: victor.e.grech@gov.mt.
} 
may occur from the deposition of radioactive particles on the skin or by internal contamination from particles that are ingested or inhaled.

Males are born in excess of females in a ratio that approximates 0.515 (M/T: male live births divided by total live births) [3]. A plethora of factors have been shown to affect M/T, with stress and toxins both decreasing M/T [3-5]. Radiation is one of the few toxins that increases M/T [6, 7]. This has been clearly shown in relation to the Chernobyl disaster of 1988 and the Windscale fire of 1957, which were both associated with an upward M/T shift and a decrease in total births in affected regions [6-10]. The phenomenon of increased $\mathrm{M} / \mathrm{T}$ also been shown in births that occur in proximity to nuclear facilities $[7,8]$.

However, worldwide artificial increases in ambient radiation levels preceded the above events. This is because after the Second World War, widespread atmospheric atomic bomb testing continued up to 1963 when the United Kingdom, United States and the Soviet Union ratified the Limited Test Ban Treaty, pledging to refrain from testing nuclear weapons in the atmosphere, underwater, or in outer space. However, the Treaty permitted underground nuclear testing, and leaks from such tests into the atmosphere were not uncommon [11]. France continued atmospheric testing until 1974, and China continued until 1980, with a total of over 2000 devices tested [12].

The worldwide annual average population radiation exposure to natural sources is $2.4 \mathrm{mSv}$ [13]. The increase in background radiation due to atomic tests alone peaked in 1962 and 1963 at about an additional $0.11 \mathrm{mSv}$ per year worldwide (5\% of the average background dose from all sources). After 1963, global background radiation levels fell progressively, down to $0.005 \mathrm{mSv}$ per year by the year 2000 and exposure was mostly due to the isotopes ${ }^{137} \mathrm{Cs},{ }^{90} \mathrm{Sr}$ and ${ }^{14} \mathrm{C}[13]$.

In theory, increases in ambient radiation levels from atomic bomb testing could have led to a rise in $\mathrm{M} / \mathrm{T}$ followed by a decline with a progressive reduction in atomic bomb testing and a waning of the effect of fallout, and these changes would be inversely correlated with total births. Indeed, several studies have indicated that this may have occurred $[6,7]$. This study was carried out in order to ascertain whether the effects of increased background radiation levels had any widespread effects on $\mathrm{M} / \mathrm{T}$ and births in the Americas, Europe, Asia and Australasia.

\section{Methods}

\subsection{Data}

Atomic bomb testing data was obtained from a catolog of these events [12]. Annual live births by gender were obtained from a World Health Organization dataset (WHO HFA (Health for All database)).

The three North American countries (Canada, USA and Mexico) were analysed separately for the period 1950-2009 (data for Mexico missing for 1950-58 and 1984). The Australasian dataset only included Australia and New Zealand (1950-2009).

Europe was analysed in three separate regions in a method that has already been established [14]. Scandinavia $\left(54^{\circ}-71^{\circ} \mathrm{N}\right)$ included Iceland, Norway, Sweden, Finland and Denmark (1950-2009). One extreme outlier was removed (Finland, 1971, M/T $=0.571)$. Central Europe $\left(40-55^{\circ} \mathrm{N}\right)$ included Austria, Belgium, Czechoslovakia (and the amalgamation of its continuation as the Czech Republic and Slovakia), France, Germany, Hungary, Luxembourg, Netherlands, Poland, Switzerland, UK \& Eire and Yugoslavia (1950-2009). Southern Europe (35-40 N) included Bulgaria, Greece, Malta, Portugal, Italy and Spain (1950-2009 - Spain missing 1970, Italy missing 2005). 
For the remaining regions, countries were only included if sufficiently large spans of identical years of data were available for analysis. Asia included Singapore, Thailand, Philippines and Japan (1950-1979). South America (1955-79) was analysed in two separate regions in a method that has already been established [15]. The equatorial region $\left(10^{\circ} \mathrm{N}-20^{\circ} \mathrm{S}\right)$ included Nicaragua, Costa Rica, Columbia and Venezuela. The southern region $\left(>20^{\circ} \mathrm{S}\right)$ comprised Uruguay, Chile and Argentina.

\subsection{Birth deficit testing}

Birth deficits were calculated by comparing observed births within affected years (periods wherein $\mathrm{M} / \mathrm{T}$ rose) with expected births. The latter were calculated by taking the mean of the previous and following 5 years relative to affected years, and multiplying this mean by the number of affected years. These short periods were chosen as it is known that M/T exhibits spontaneous secular fluctuation [16]. This methodology has been previously utilized for the calculation of birth deficits after the Chernobyl accident [10].

\subsection{Statistics}

Excel was used for data entry, overall analysis and charting. The quadratic equations of Fleiss were used for exact calculation of 95\% confidence intervals for ratios [17]. SPSS was used for the calculation of Pearson correlations. Chi-square tests for trend were used for annual male and female births. These were performed using the Bio-Med-Stat Excel add-in for contingency tables [18], which is based on the original work by Cochran and Armitage [19,20]. A $p$ value $\leq 0.05$ was taken to represent a statistically significant result. The null hypothesis was that there were no significant changes in $\mathrm{M} / \mathrm{T}$ before and after the ratification of the Limited Test Ban Treaty.

\section{Results}

\subsection{M/T patterns and atomic bomb tests}

This paper studied 1033775478 live births. M/T data in 5 year intervals is shown in Table 1. Several regions (Canada, USA, Mexico, Central and Southern Europe and South America $10^{\circ} \mathrm{N}-20^{\circ} \mathrm{S}$ ) display similar trends: an initial decline in M/T from the early $1950 \mathrm{~s}$, followed by a rise in the $1960 \mathrm{~s} / 70 \mathrm{~s}$, with a decline thereafter. This rise is superimposed over an overall declining trend in M/T with almost all of these changes occurring at highly statistically significant levels (Table 2).

Asia exhibited a trimodal M/T pattern (Fig. 1). M/T rose up to 1957 (chi $=560.0, p<0.0001$ ), fell over 1957-59 (chi $=541.5, p<0.0001)$, rose again between 1959 and $1962(\mathrm{chi}=441.1, p<0.0001)$, fell between 1962 and $1965(\mathrm{chi}=194.5, p<0.0001)$, rose over 1965-70 (chi $=88.0, p<0.0001)$, and declined between 1970-79 $(\mathrm{chi}=276.6, p<0.0001)$. M/T loosely followed the pattern of annual number of atomic bomb tests carried out worldwide and correlated significantly with this variable $(r=0.4, p=0.02)$.

There was a continually rising trend in M/T for South America $>20^{\circ} \mathrm{S}(1955-79$, chi $=80.1, p<0.0001)$. There were no significant trends related to the abovementioned eras for Scandinavia and Australasia.

Overall, $94.5 \%$ of the data showed a uniform reduction in M/T between the early $1950 \mathrm{~s}$ to the late $1960 \mathrm{~s}$, followed by an increase to the mid-1970 s, with a subsequent decline. 


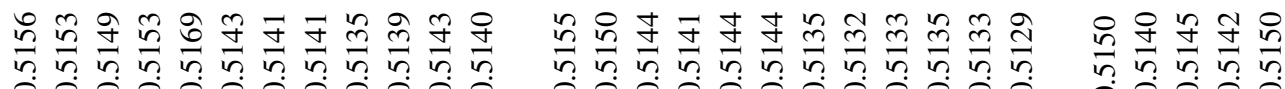
00000000000000000000000000

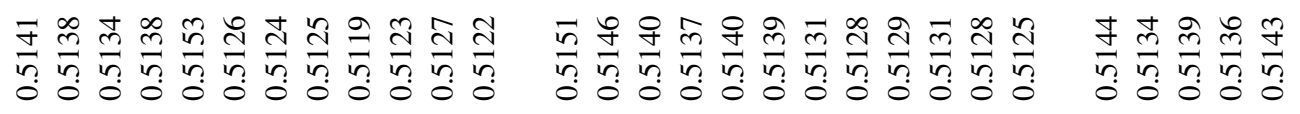

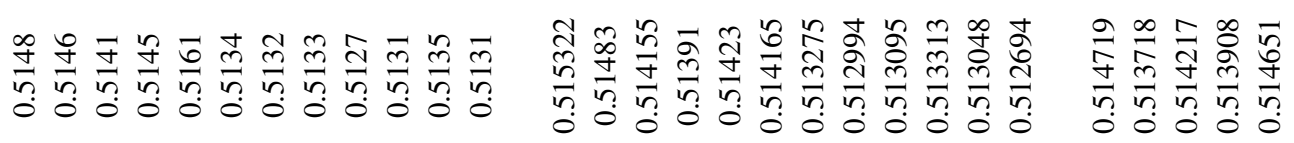

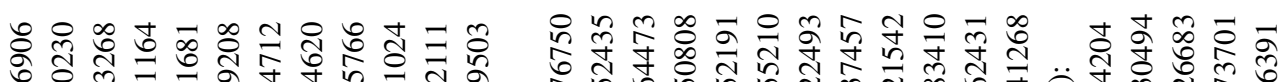

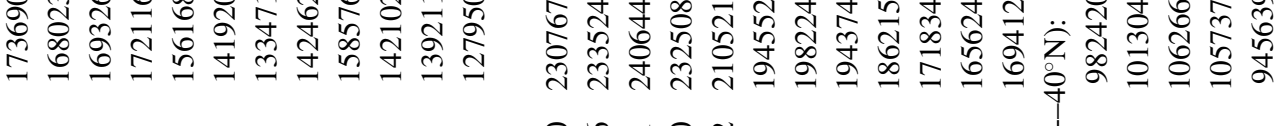

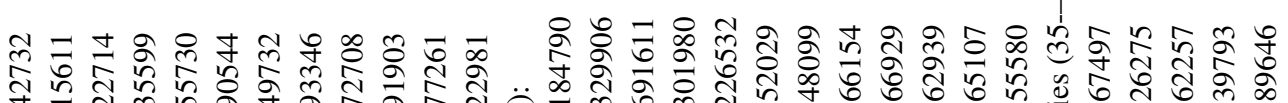

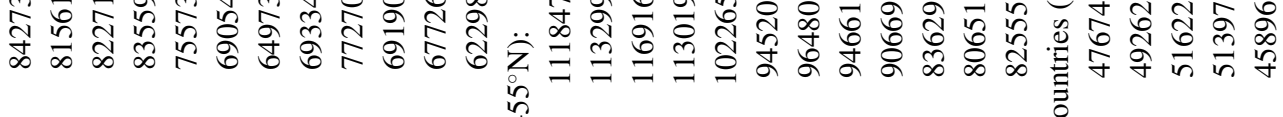

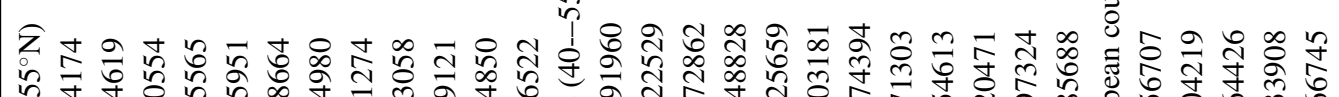

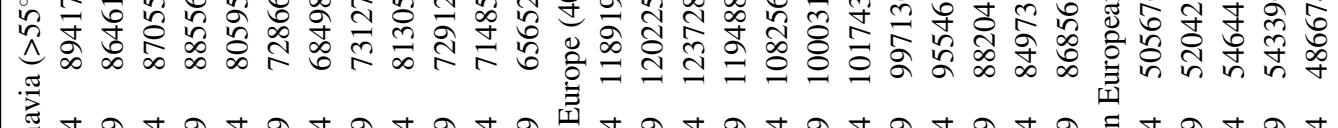

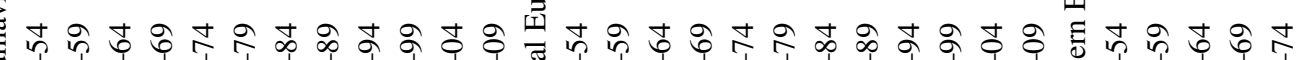

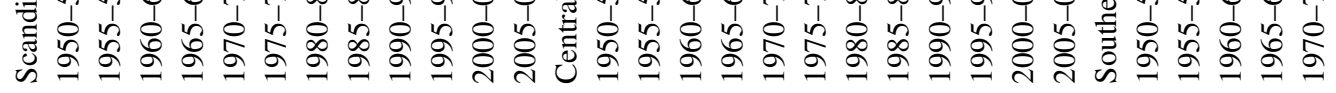

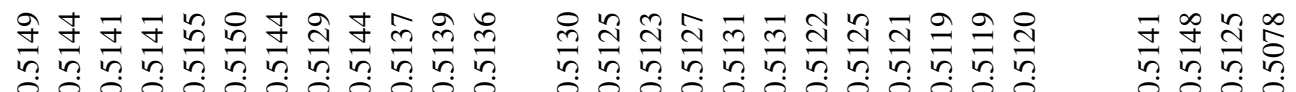

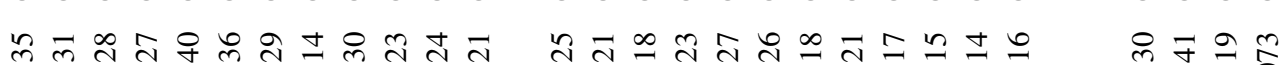

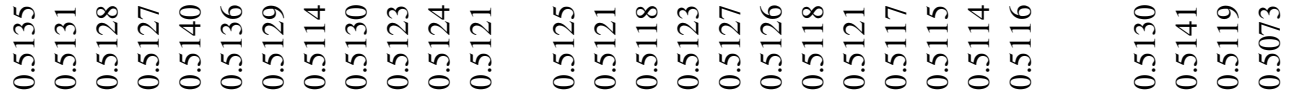

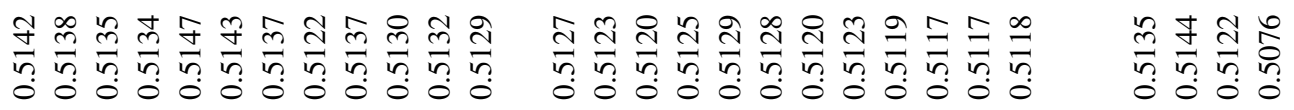

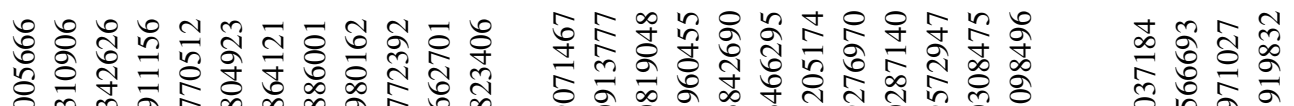

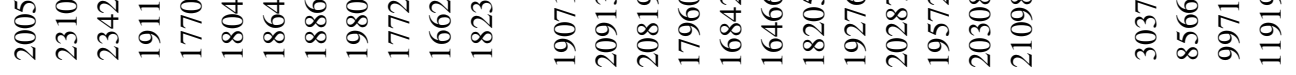

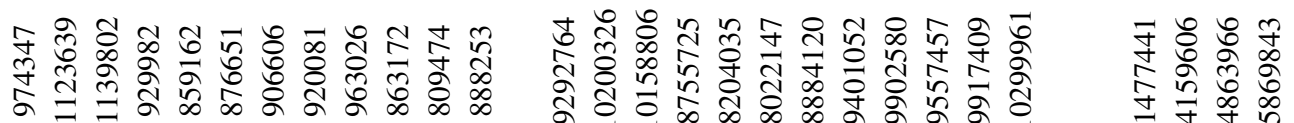

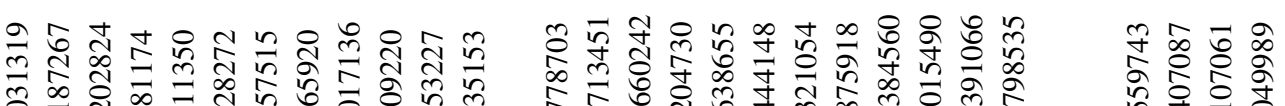

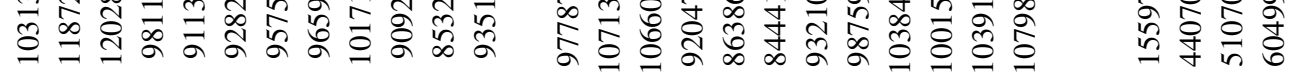

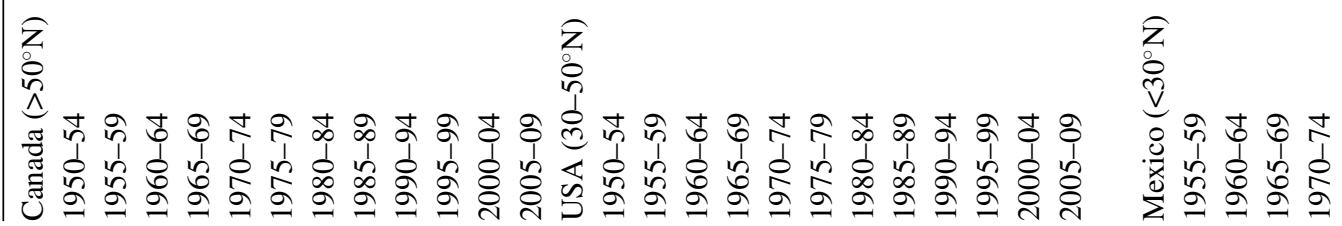




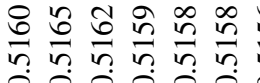

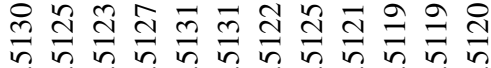

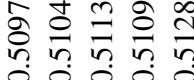

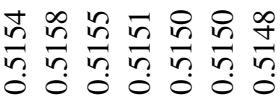

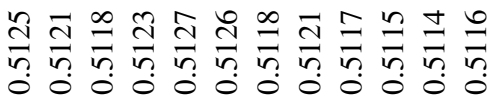

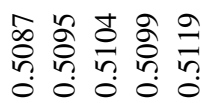

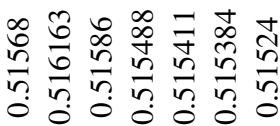

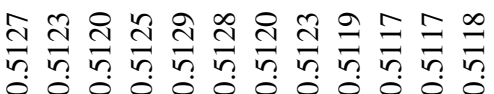

ถิํํ을

$\infty$ 응

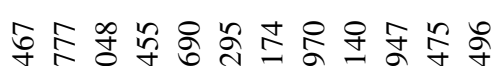

윽

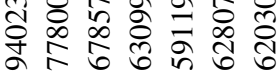

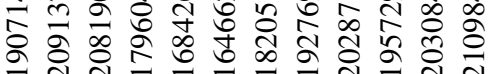

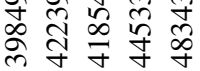

ํำ

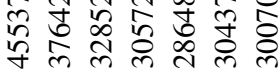

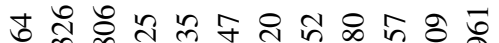

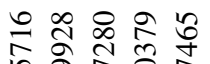
人ิ ळ \&

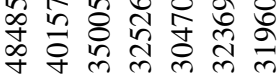

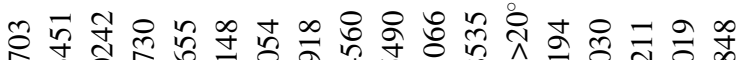

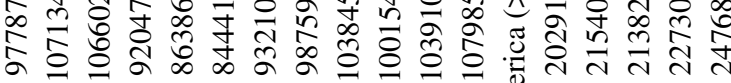

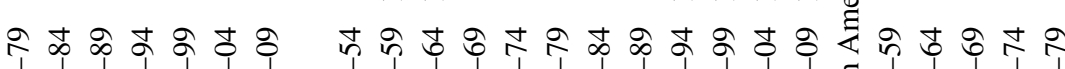
尛。 范 ज़

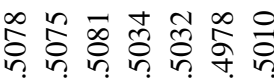

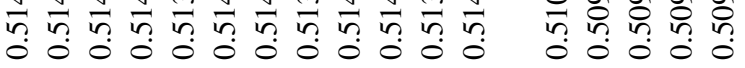

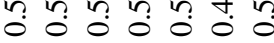
๙ิ

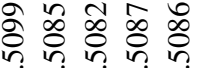

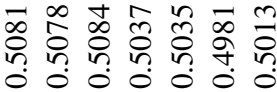

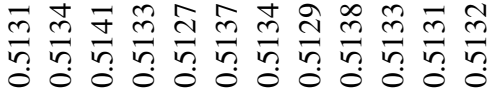
m น तु?

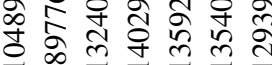

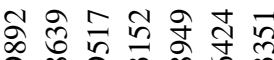

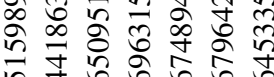

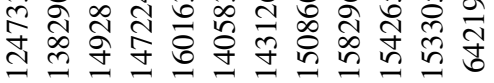

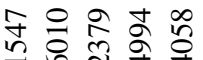
工 I士

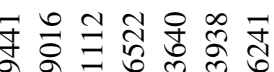

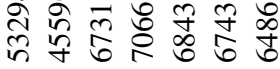

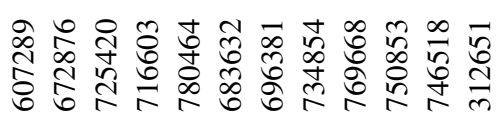

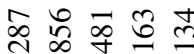

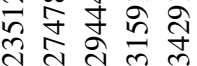

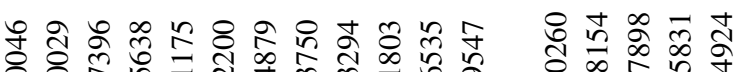

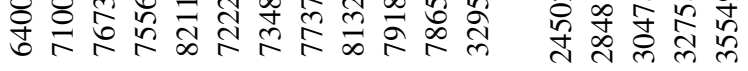

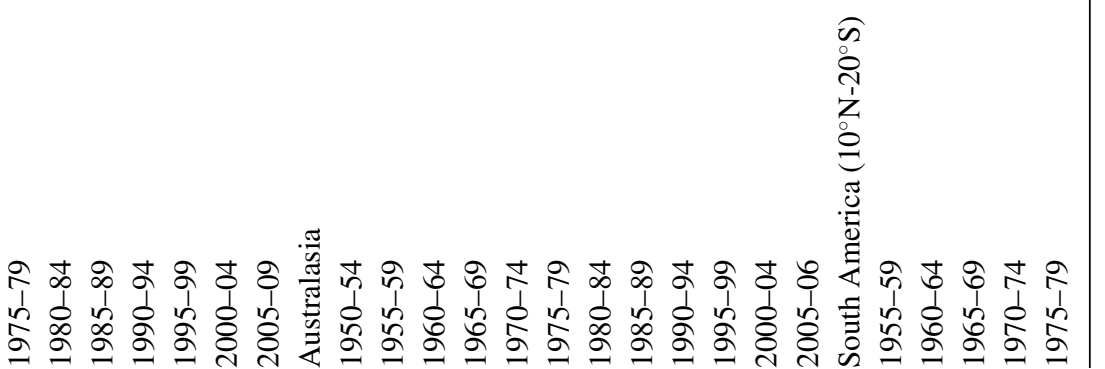




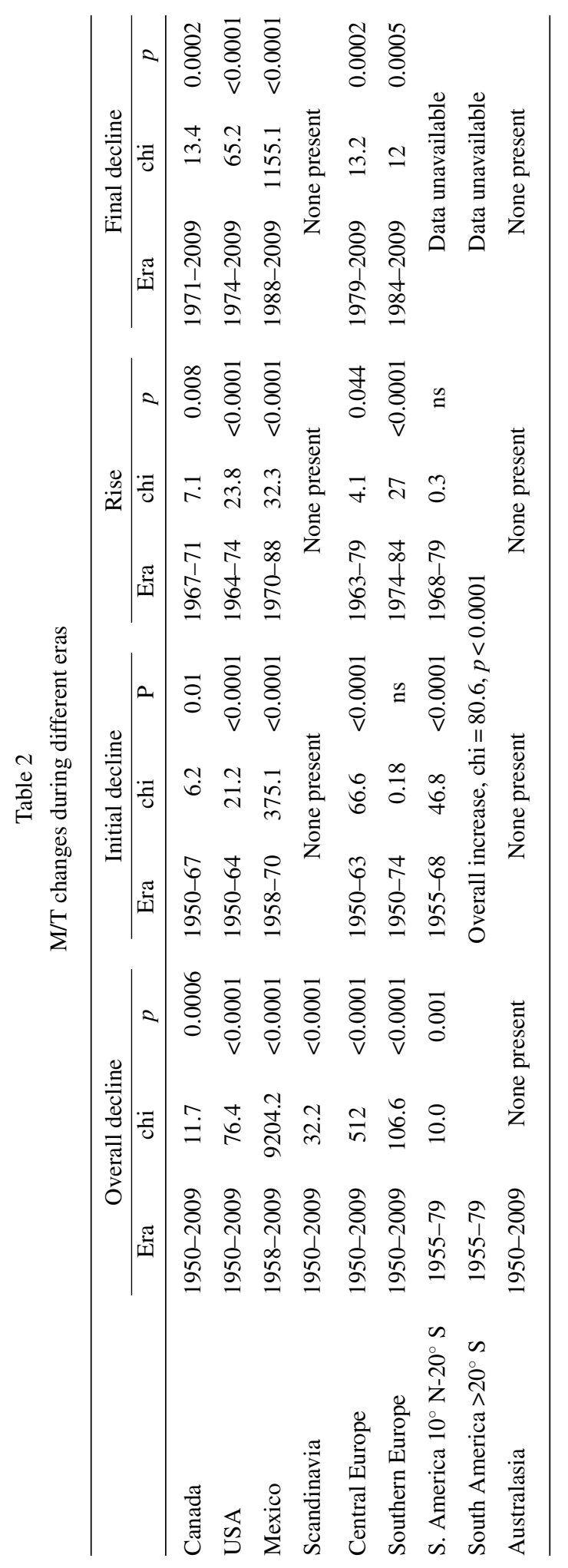




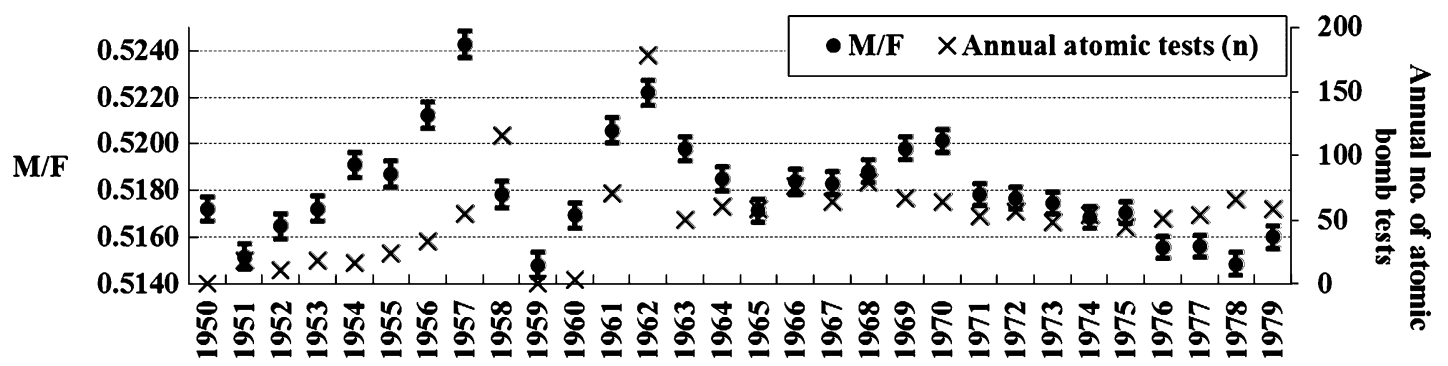

Fig. 1. Annual M/T vs. annual number of atmospheric atomic bomb tests for Asia, 1950-79.

Table 3

Correlations for $\mathrm{M} / \mathrm{T}$ with live births for time periods as per second column in Table 2 (Asia 1950-2009)

\begin{tabular}{lcc}
\hline & $r$ & $p$ \\
\hline Canada & 0.05 & $\mathrm{~ns}$ \\
USA & -0.51 & $<0.0001$ \\
Mexico & -0.75 & $<0.0001$ \\
Scandinavia & 0.28 & 0.03 \\
Central Europe & 0.74 & $<0.0001$ \\
Southern Europe & -0.63 & $<0.0001$ \\
S. America $10^{\circ} \mathrm{N}-20^{\circ} \mathrm{S}$ & -0.34 & $\mathrm{~ns}$ \\
S. America $>20^{\circ} \mathrm{S}$ & 0.46 & 0.02 \\
Asia & -0.39 & 0.03 \\
Australasia & -0.2 & $\mathrm{~ns}$ \\
\hline
\end{tabular}

\section{2. $M / T$ and births}

Annual M/T was correlated with annual births for each of the abovementioned regions (Table 3 ). Overall, $66 \%$ of the data showed a negative correlation of $\mathrm{M} / \mathrm{T}$ with total births, and these were the regions which exhibited the abovementioned pattern, with rise in M/T in the $1970 \mathrm{~s}$. A positive correlation was found in $27 \%$ of the data while $7 \%$ showed no correlation.

\subsection{Birth deficits}

South America was not included in birth deficit calculations as the rise in $\mathrm{M} / \mathrm{T}$ continued to the end of the dataset. The birth deficit for the other countries in Table 3 with significant correlations of total births with M/T (North America, Europe and Asia) was estimated at 10090701 (Table 4).

\section{Discussion}

After the bombing of Hiroshima and Nagasaki in 1945, studies exhibited only partial evidence for an influence on M/T by radiation [21, 22]. However, it was shown that perinatal and infant mortality were more robustly associated with radiation exposure [23, 24]. 


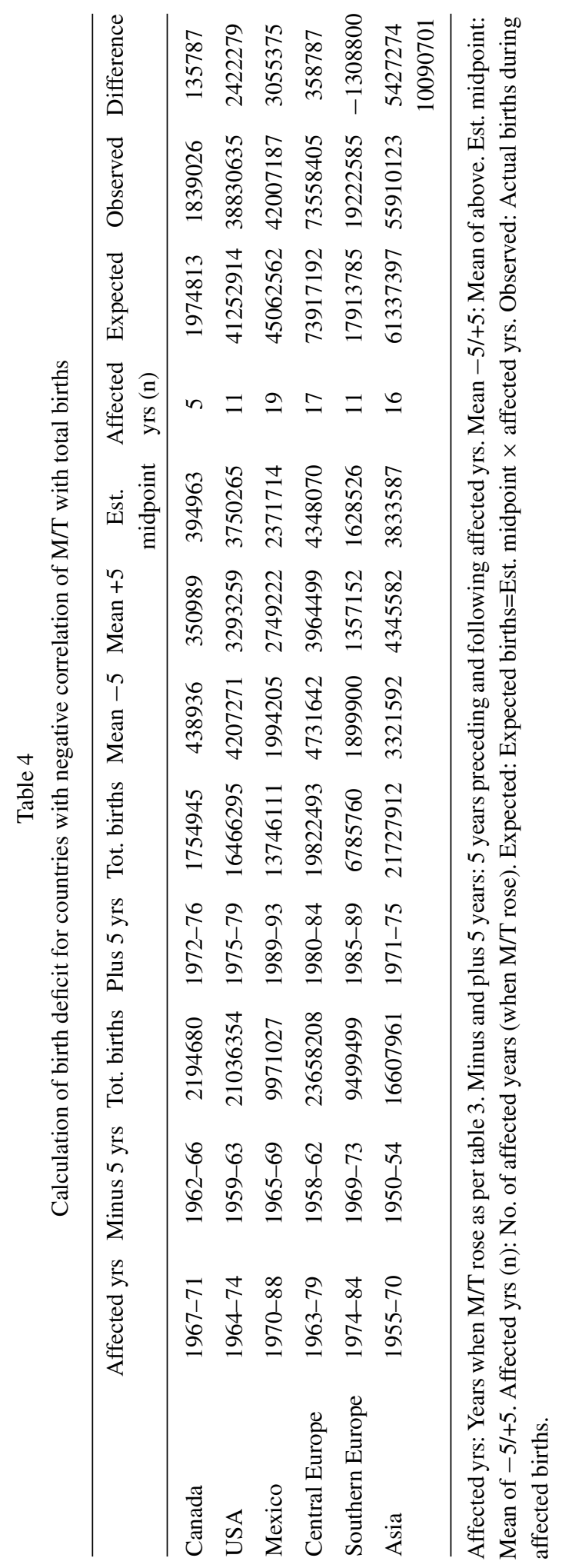


94.5\% of the data in this paper appears to adhere to trends more recently described and attributed to a delayed increase in ambient radiation from fallout released and dispersed by atmospheric atomic weapons testing prior to the Partial Test Ban Treaty in 1963. The pattern consists of a uniform reduction in M/T between the early $1950 \mathrm{~s}$ to the late $1960 \mathrm{~s}$, followed by an increase to the mid-1970 s, with a subsequent decline [7].

A report by the European Committee on Radiation Risk on infant mortality concluded that there was as a $2-3 \%$ increase in infant mortality per $\mathrm{mSv}$ of parental exposure (equivalent to a relative risk of 1.1 to $1.2 / \mathrm{mSv}$ per year) based on data for the period 1959-1963 [25]. Further evidence for radiation effects on stillbirths and certain birth defects from another study tallied with doses in the same ranges $(1.3-2.3 / \mathrm{mSv}$ per year) [26]. Indeed, this study has shown that in most regions, annual M/T correlated negatively with annual births. Moreover, this study has conservatively calculated a deficit of over 10 million births that may be attributed to ambient radiation effects from atomic weapon testing. The estimate was conservative as only eras wherein the M/T slope was positive where included, and the years immediately following these periods where the trend reversed were not included.

This study's findings indicate that elevated levels of man-made ambient radiation may have reduced total global births, affecting pregnancies carrying female foetuses more than those carrying male foetuses and thereby skewing $\mathrm{M} / \mathrm{T}$ toward a higher male proportion. This is because ionising radiation is a unique toxin as maternal exposure produces the opposite effect to paternal exposure. Prospective fathers who are irradiated sire an excess of males [27], while prospective irradiated mothers give birth to an excess of females [21]. Radiation is also unique in that it appears to be the only toxin that elevates M/T when both genders are equally exposed [6].

It has been hypothesised that a radiation-induced X-linked recessive lethal gene in a mother's germ cell line would have no effect on a heterozygous daughter but would be lethal if passed on to a male zygote. Furthermore, $\mathrm{X}$-linked recessive lethal mutations in mothers would shift M/T to favour female offspring. Moreover, X-linked dominant lethal mutations in mothers would be equally lethal to both genders [22]. $\mathrm{X}$-linked dominant mutations induced in fathers would only inhibit female offspring. Recessive X-linked lethal mutations in fathers would not influence $\mathrm{M} / \mathrm{T}$ as sons do not receive the paternal X-chromosome and daughters inherit a protective second $\mathrm{X}$-chromosome from their mother [22].

$\mathrm{M} / \mathrm{T}$ is therefore distorted by radiation through increased foetal mortality that affects female more than male conceptuses. It is speculated that the skew toward higher female mortality may be due to the fact that the $\mathrm{X}$ chromosome contains more genetic material and is larger, and hence, may be physically more easily hit by ionising radiation. Another possibility is that ova and sperm somehow afford their genetic material different levels of protection [6].

Earlier studies estimated approximately 8000 lost births from the Windscale fire of 1957 [9] and over two million births lost from the Chernobyl incident of 1986 [10]. It appears that mankind has also significantly altered $\mathrm{M} / \mathrm{T}$ through atomic weapon testing. Living close to nuclear power plants has also been shown to increase M/T [7]. Furthermore, and unrelated to radiation effects, selective female foetal abortion in Asian cultures wherein males are preferred has led to an estimated 100 to 200 million missing women worldwide [28, 29]. Mankind's actions have therefore significantly depressed the species' female live-birth proportion.

\section{Acknowledgements}

Dr. Mie Inoue and Dr. Gauden Galea from the World Health Organization. 


\section{References}

[1] Szasz FM. The Day The Sun Rose Twice: The Story of the Trinity Site Nuclear Explosion July 16, 1945. New Mexico: University of New Mexico Press, 1984.

[2] Vanmarcke H. United Nations Scientific Committee on the Effects of Atomic Radiation (UNSCEAR): Sources of ionizing radiation. Beschermingsonderzoek; Departement Stralings: 2000.

[3] James WH. The human sex ratio. Part 1: A review of the literature. Hum Biol. 1987;59:721-52.

[4] James WH. The human sex ratio. Part 2: A hypothesis and a program of research. Hum Biol. 1987:59:873-900.

[5] Catalano RA. Sex ratios in the two Germanies: A test of the economic stress hypothesis. Hum Reprod. 2003;18:1972-5.

[6] Scherb H, Voigt K. Trends in the human sex odds at birth in Europe and the Chernobyl Nuclear Power Plant accident. Reprod Toxicol. 2007;23:593-9.

[7] Scherb H, Voigt K. The human sex odds at birth after the atmospheric atomic bomb tests, after Chernobyl, and in the vicinity of nuclear facilities. Environ Sci Pollut Res Int. 2011;18:697-707.

[8] Scherb H, Voigt K, Kusmierz R. The human sex odds at birth in France: A preliminary geo-spatial-temporal approach in the vicinity of French nuclear facilities (NF). In: Wittmann J, Müller M, editors. Simulation in den Umwelt- und Geowissenschaften, Workshop Leipzig 2013. Aachen: Shaker Verlag; 2013. pp. 23-38.

[9] Grech V. Births and male: Female birth ratio in Scandinavia and the United Kingdom after the Windscale fire of October 1957. Int J Risk Saf Med. 2014;26:45-53.

[10] Grech V. The Chernobyl accident, the male to female ratio at birth and birth rates. Acta Medica (Hradec Kralove). 2014;57(2):62-7.

[11] U.S. Congress, Office of Technology Assessment. The Containment of Underground Nuclear Explosions. Washington: U.S. Government Printing Office, 1989.

[12] Mikhailov VN. Catalog of worldwide nuclear testing. New York: Begell-Atom, LLC; 1999.

[13] Vanmarcke H. UNSCEAR 2000: Sources of ionizing radiation. Boeretang: Departement Stralingsbeschermingsonderzoek, 2000.

[14] Grech V, Savona-Ventura C, Vassallo-Agius P. Research pointers: Unexplained differences in sex ratios at birth in Europe and North America. BMJ. 2002;324:1010-1.

[15] Grech V. Secular trends in sex ratios at birth in South America over the second half of the 20th century. J Pediatr. (Rio J). 2013;pii:S0021-7557.

[16] Gini C. Sulla probabilita che termini di una serie erratica sieno tutti crescenti (o non decrescenti) ovvero tutti decrescenti (o non crescenti) con applicazioni ai rapporti dei sessi nascite umane in intervalli successivi e alle disposizioni dei sessi nelle fratellanze umane. Metron. 1955;17:1-41.

[17] Fleiss JL. Statistical methods for rates and proportions. New York: John Wiley and Sons, 1981:14-15 (2nd edition).

[18] Slezák P. Microsoft Excel add-in for the statistical analysis of contingency tables. Int J Innovation Educ Res. 2014;2:90-100.

[19] Cochran WG. Some methods for strengthening the common chi-squared tests. Biometrics. 1954;10:417-51.

[20] Armitage P. Tests for Linear Trends in Proportions and Frequencies. Biometrics. 1955;11:375-86.

[21] Schull WJ, Neel JV. Radiation and the sex ratio in man. Science. 1958;128:343-8.

[22] Vogel F, Motulsky AG. Human genetics. 2nd ed. Berlin: Springer; 1986.

[23] Sternglass EJ. Environmental radiation and human health. In: Neyman J, editor. Symposium on Mathematical Statistics and Probability. Berkeley: University of California Press; 1971. pp. 145-221.

[24] Whyte RK. First day neonatal mortality since 1935: Re-examination of the Cross hypothesis. BMJ. 1992;304:343-6.

[25] European Committee on Radiation Risk (ECRR). The health effects of ionizing radiation, exposure at low doses for radiation protection purposes. Aberystwyth; Green Audit Press, 2003.

[26] Scherb H, Weigelt E. Congenital malformation and stillbirth in Germany and Europe before and after the Chernobyl Nuclear Power Plant accident. Env Sci Pollut Res 2003;1:117-25

[27] James WH. Ionizing radiation and offspring sex ratio. J Epidemiol Community Health. 1997;51:340-1.

[28] Sen A. Missing women. BMJ. 1992;304:587-8.

[29] Diamantopoulou A. Violence against Women: Zero Tolerance. Lisbon, Centro de Congressos de Lisboa, 4-6 May 2000. http://europa.eu/rapid/press-release_SPEECH-00-161_en.pdf 